\title{
On-line electrochemistry-bioaffinity screening with parallel HR-LC-MS for the generation and characterization of modified p38 $\alpha$ kinase inhibitors
}

\author{
David Falck • Jon S. B. de Vlieger • Martin Giera • \\ Maarten Honing $\cdot$ Hubertus Irth • \\ Wilfried M. A. Niessen • Jeroen Kool
}

Received: 9 September 2011 /Revised: 26 November 2011 / Accepted: 15 December 2011 /Published online: 8 January 2012

(C) The Author(s) 2012. This article is published with open access at Springerlink.com

\begin{abstract}
In this study, an integrated approach is developed for the formation, identification and biological characterization of electrochemical conversion products of $\mathrm{p} 38 \alpha$ mitogen-activated protein kinase inhibitors. This work demonstrates the hyphenation of an electrochemical reaction cell with a continuous-flow bioaffinity assay and parallel LCHR-MS. Competition of the formed products with a tracer (SKF-86002) that shows fluorescence enhancement in the orthosteric binding site of the $\mathrm{p} 38 \alpha$ kinase is the readout for bioaffinity. Parallel HR-MS ${ }^{\mathrm{n}}$ experiments provided information on the identity of binders and non-binders. Finally, the data produced with this on-line system were compared to electrochemical conversion products generated off-line. The electrochemical conversion of 1-\{6-chloro-5-[(2R,5S)-4-(4fluorobenzyl)-2,5-dimethylpiperazine-1-carbonyl]-3aHindol-3-yl -2-morpholinoethane-1,2-dione resulted in eight products, three of which showed bioaffinity in the continuousflow p $38 \alpha$ bioaffinity assay used. Electrochemical conversion
\end{abstract}

$\overline{\text { David Falck and Jon S. B. de Vlieger equally contributed to this work. }}$

Published in the special paper collection on Electrochemistry-Mass Spectrometry with guest editors Uwe Karst and Martin Vogel.

Electronic supplementary material The online version of this article (doi:10.1007/s00216-011-5663-2) contains supplementary material, which is available to authorized users.

D. Falck · J. S. B. de Vlieger $\cdot$ M. Giera $\cdot$ H. Irth •

W. M. A. Niessen $\cdot$ J. Kool $(\bowtie)$

Division of BioMolecular Analysis, Faculty of Sciences,

VU University Amsterdam,

De Boelelaan 1083,

$1081 \mathrm{HV}$, Amsterdam, the Netherlands

e-mail: J.Kool@few.vu.nl

M. Honing

DSM Resolve,

PO Box 18, 6160 MD, Geleen, the Netherlands of BIRB796 resulted, amongst others, in the formation of the reactive quinoneimine structure and its corresponding hydroquinone. Both products were detected in the p38 $\alpha$ bioaffinity assay, which indicates binding to the $\mathrm{p} 38 \alpha$ kinase.

Keywords Electrochemical oxidation · p38 mitogenactivated protein kinase $\cdot$ High resolution mass spectrometry . Hyphenation · Bioassays

\section{Introduction}

Electrochemistry (EC) is increasingly described as a tool to support the formation and identification of drug oxidation products [1]. Efforts are reported to mimic a human metabolite profile [2] or to produce specific reactive metabolite species [3]. The application of electrochemical techniques specifically focused at drug development is reviewed by Hillard et al. [4]. These applications are mainly directed at the study of reactive oxygen species, oxidation and reduction of prodrugs, and the alkylation of DNA. Bauman and Karst [5] recently described the principles and use of on-line electrochemistry-mass spectrometry (EC-MS) in drug metabolism studies. Jurva et al. systematically compared the oxidation of drugs by EC-MS and by cytochrome P450s [6]. This approach provides chemical information on the products formed by electrochemistry and facilitates the comparison with in vitro incubation models $[7,8]$. The chemical information obtained can eventually be used to correlate biological action of already characterized metabolites to the products analysed. However, this is not feasible for newly formed products for which no biological data are yet available. Still, few examples in EC-related drug metabolism 
studies employ detection of biological activity $[9,10]$ and, to the best of our knowledge, none tested for a specific target enzyme or receptor. More importantly, in studies employing EC-MS or EC-LC-MS, biological testing seems to be a completely new development. This is surprising because the biological activity of the metabolites towards the drug target is of utmost importance for the efficacy of a drug. For many years, we have been developing hyphenated screening assays to obtain chemical and biological information in a combined manner [11]. This resulted in several approaches to assess bioaffinity, e.g., on-line receptor binding [12], enzyme activity assessment [13], bacterial growth inhibition [14], as well as several other strategies which allowed us to identify and characterize bioactive compounds [15-17] in (complex) mixtures. These mixtures included natural extracts, crude synthesis products, medicinal chemistry compound libraries, degradation products by light or harsh chemical conditions, as well as in vitro metabolic incubations.

The implementation of a device for electrochemical oxidation in our on-line screening platform would lead to a fully automated process of formation of drug-related chemical entities followed by their simultaneous chemical and biological characterization. This leads to a quick feedback between the modifications of a lead compound and their consequences for binding to the drug target. Furthermore, instable and/or reactive products could be analysed directly after their formation and as such have less chance of degradation.

In this paper, we describe the hyphenation of EC with our recently developed liquid chromatography (LC)-on-line p38 $\alpha$ mitogen-activated protein kinase binding assay (p38 $\alpha$ bioaffinity assay) with parallel high resolution MS [18]. EC provides relatively clean samples and has shown to facilitate the formation of interesting molecules for drug research [19]. The p38 $\alpha$ mitogen-activated protein kinase (p38 kinase) is a prominent example of a drug target kinase [20] and is heavily involved in inflammation processes [21]. The hyphenation of these techniques to develop a fully integrated platform can facilitate the hitto-lead selection process in drug discovery. This complete hyphenation of EC with LC and ultimately with parallel detection by $\mathrm{p} 38 \alpha$ bioaffinity assay and high resolution MS combines modification with separation, bioaffinity determination and structure elucidation on a new level of integration.

\section{Materials and methods}

Chemicals

Acetonitrile, methanol (LC-MS grade), and formic acid (ULCMS grade) were obtained from Biosolve (Valkenswaard, the
Netherlands). Water was produced by a Milli-Q device of Millipore (Amsterdam, the Netherlands). Nitrogen 5.0 was purchased from Praxair (Vlaardingen, the Netherlands) and used in all MS experiments. SKF-86002 (SKF) was delivered by Merck KGaA (Darmstadt, Germany). Enzyme-linked immunosorbent assay blocking reagent was purchased from Roche Diagnostics (Mannheim, Germany). Ammonium acetate and ammonium hydrogen carbonate were obtained from Mallinckrodt Baker (Deventer, the Netherlands). Fused silica tubing (250- $\mu \mathrm{m}$ inner and $375-\mu \mathrm{m}$ outer diameter) covalently coated with polyethylene glycol was obtained from SigmaAldrich (Schnelldorf, Germany). Human recombinant p38 $\alpha$ kinase, BIRB796, TAK715, 1-(6-chloro-5-((2R,5S)-4-(4-fluorobenzyl)-2,5-dimethylpiperazine-1-carbonyl)-3aH-indol-3yl)-2-morpholinoethane-1,2-dione (DMPIP), and SB203580 were a kind gift of MSD Research Laboratories (Oss, the Netherlands). Structures of the kinase inhibitor standards used can be found in Fig. 1. All other chemicals were from SigmaAldrich (Schnelldorf, Germany).

\section{Instrumentation}

A schematic representation of the complete on-line setup is shown in Fig. 2. The system consists of four modules: (a) an electrochemical reaction cell, (b) an LC system, (c) a continuous-flow bioaffinity assay unit, equipped with a fluorescence detector, and (d) a mass spectrometer.
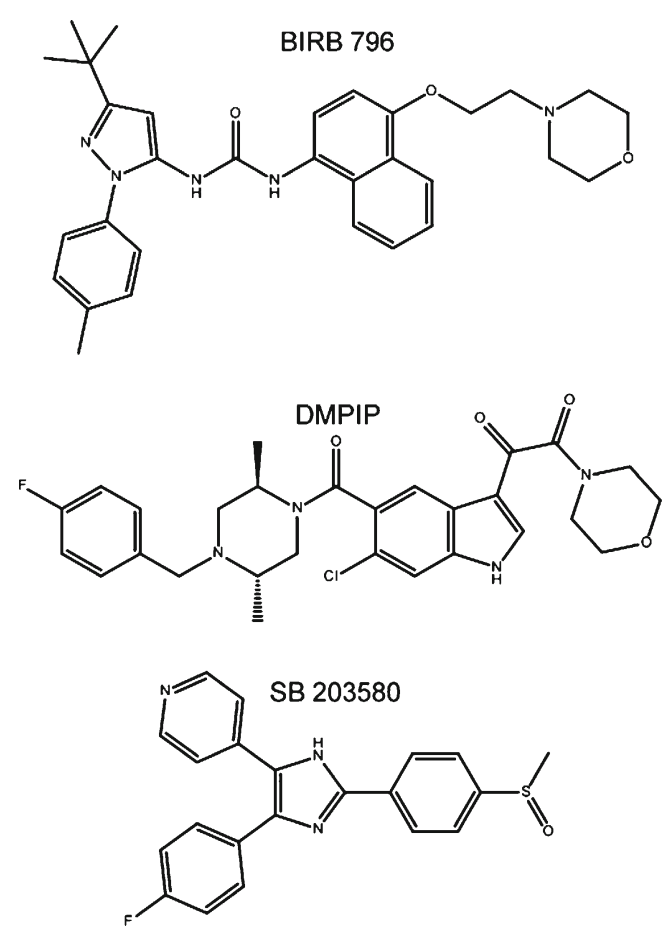

Fig. 1 Structures of the kinase inhibitors used for electrochemical conversion experiments 


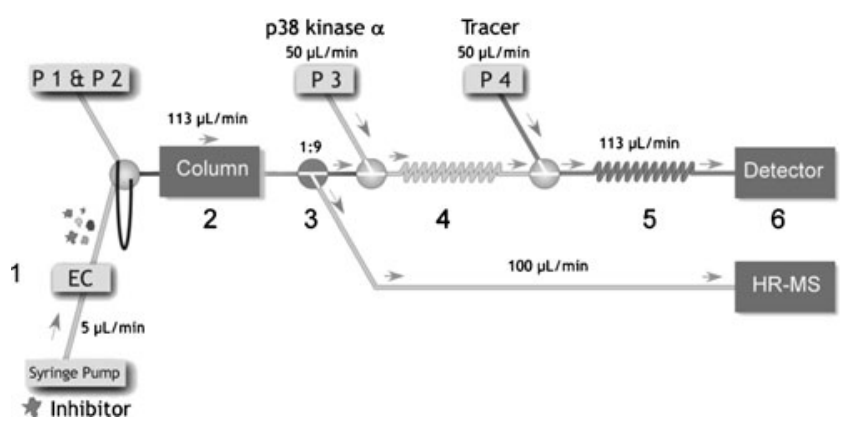

Fig. 2 Scheme of the on-line setup. (1) On-line electrochemical conversion of inhibitor. (2) Gradient LC separation of products formed. (3) Split of $1: 9$ to MS and p38 $\alpha$ bioaffinity assay. (4) Reaction coil for enzyme binding. (5) Addition of tracer molecule. (6) Detection of enzyme tracer complex by fluorescence and parallel HR-MS ${ }^{\mathrm{n}}$ for structural information of binders

A Roxy electrochemical reaction cell (Antec Leyden, Zoeterwoude, the Netherlands) equipped with a glassy carbon electrode was controlled by the Decade II Potentiostat either manually or under Dialogue software control (Antec Leyden). The $10 \mu \mathrm{M}$ kinase inhibitor standards, dissolved in $25 \% \mathrm{ACN}$ and $75 \% 1 \mathrm{mM}$ aqueous buffer, were infused at a flow rate of $5 \mu \mathrm{L} / \mathrm{min}$ with a Harvard Apparatus (Hollister, USA) syringe pump. The conversion products were collected either in an autosampler vial ("off-line" mode) or in $100 \mu \mathrm{L}$ volume PEEK tubing ("on-line" mode) serving as an injection loop mounted in a remote controlled six port valve (VICI, Schenkon, Switzerland).

In the off-line mode, collected fractions were injected via the autosampler, whereas in the on-line mode the six port valve with the $100 \mu \mathrm{L}$ PEEK tubing acted as the injection valve to a Shimadzu LC system ('s Hertogenbosch, the Netherlands), consisting of two LC-10ADvp pumps, a DGU-14A solvent degasser, a SIL-10ADvp auto injector, two CTO-10ASvp column oven, an SPD-10Avp UVdetector and a SCL-10Avp system controller. The LC separation was performed on a Waters Xbridge C18 column $(2.1 \times 100 \mathrm{~mm}$ I.D., $3.5 \mu \mathrm{m}$ particles $)$. The mobile phases consisted of $99 \%$ water with $1 \%$ methanol (solvent A) and $1 \%$ water with $99 \%$ methanol (solvent B), both containing $0.01 \%$ formic acid. A generic gradient was applied for the separation: isocratic for $2 \mathrm{~min}$ at $20 \% \mathrm{~B}$, gradient to $90 \% \mathrm{~B}$ until $18 \mathrm{~min}$, isocratic at $90 \% \mathrm{~B}$ until $22 \mathrm{~min}$, a gradient back to $20 \% \mathrm{~B}$ until $23 \mathrm{~min}$, and isocratic re-equilibration at $20 \% \mathrm{~B}$ until the end of the run at $30 \mathrm{~min}$. The flow rate was $113 \mu \mathrm{L} / \mathrm{min}$. The column temperature was kept at $40{ }^{\circ} \mathrm{C}$. All standards eluted with significant retention, which provided sufficient resolution for the separation of products with slightly differing polarities.

Initial off-line experiments were performed with the EC unit and an LC-MS system, without the p38 bioaffinity assay attached, in order to optimize the EC conditions. For this, the LC system was coupled via an electrospray ionization (ESI) interface to a Thermo Finnigan LCQ Deca ion trap mass spectrometer (LRMS; Breda, the Netherlands). Experimental conditions for the ion trap MS were as follows: Capillary temperature $200{ }^{\circ} \mathrm{C}$, sheath gas flow 45 arbitrary units, aux gas flow 5 arbitrary units, source voltage $5 \mathrm{kV}$ and capillary voltage $6 \mathrm{~V}$. The instrument was used in positive-ion ESI mode for full spectra acquisition between $\mathrm{m} / \mathrm{z} 150$ and 650 .

In on-line experiments with the complete setup, a postcolumn split was applied (see Fig. 2), with $13 \mu \mathrm{L} / \mathrm{min}$ of the LC mobile phase being directed to the $\mathrm{p} 38 \alpha$ bioaffinity assay and $100 \mu \mathrm{L} / \mathrm{min}$ to the MS system. The post-column fluorescence enhancement based bioaffinity assay towards the $\mathrm{p} 38 \alpha$ kinase was identical to the system previously described by us [18]. Important features of the system are shown in Fig. 2. Competition of the formed products with a tracer (SKF) that shows fluorescence enhancement in the orthosteric binding site of the $\mathrm{p} 38 \alpha$ kinase is the readout for bioaffinity. Stability of the flow system is essential for the quality of the assay as small changes in the reaction parameters have relatively pronounced consequences in the signal. Therefore, a stable reagent flow is important in order to keep the noise to a minimum. This was achieved by a linear setup of an LC pump, a pulse dampener, a restriction capillary, and a superloop. The state-of-the-art LC pump delivered a constant flow of water. The pulse dampener was based on an impermeable membrane and had a comparably extensive water reservoir. The restriction capillary was chosen to produce ca 70 bar backpressure at the applied flow rate of $50 \mu \mathrm{L} / \mathrm{min}$. As a result, a constant and stable flow entered the superloop. The superloop served as a reagent reservoir of constant volume which released exactly the same flow rate as it received. Compared to a delivery by the pump alone, reagents were also more easily cooled and pump maintenance was reduced which further improved the stability of the system.

Parallel to the p38 $\alpha$ bioaffinity assay, the electrochemical conversion products were analysed using a Shimadzu iontrap time-of-flight hybrid mass spectrometer (LC-IT-TOFMS), equipped with an ESI source and operated in positiveion mode to obtain accurate $m / z$ values for $[\mathrm{M}+\mathrm{H}]^{+}$and fragment ions. The ESI needle voltage was set to $4.5 \mathrm{kV}$, while the source heating block and curved desolvation line temperature were set to $200{ }^{\circ} \mathrm{C}$. Drying gas pressure was set at $62 \mathrm{kPa}$ and nebulizing gas was applied at a flow-rate of $1.5 \mathrm{~L} / \mathrm{min} . \mathrm{MS}^{2}$ and $\mathrm{MS}^{3}$ spectra were acquired in datadependent mode with the following settings: full-spectrum MS with $m / z$ 200-650, MS ${ }^{2}$ with $m / z$ 150-650, and $\mathrm{MS}^{3}$ acquisition with $\mathrm{m} / \mathrm{z} 100-650$ with ion accumulation time of $10 \mathrm{~ms}$, precursor isolation width of $3 \mathrm{Da}$, and collision energy set at $75 \%$ for TAK 715 and $50 \%$ for all other compounds. The accurate-mass fragmentation data obtained were used for structure identification. External calibration of the instrument was based on sodium TFA clusters and allowed a mass accuracy lower than $5 \mathrm{ppm}$. From the 
measured accurate mass, the elemental composition of the products and their fragment ions were calculated. In order to extract the relevant elemental compositions, restrictions were applied to exclude those which have more atoms of any kind than the substrate plus possible modifications. This is reasonable because the products are linked to the substrate by electrochemical modification. For fragments, the elemental composition of the precursor ion was used as restriction. The few compositions left were analysed for electrochemical modifications possibly leading to the formation of products with a specific composition. Where CID fragments were concerned, this analysis was based on reasonable neutral losses. The procedure was sufficient to restrict the discussion to only one elemental composition.

\section{Optimization of electrochemical conversion}

For flow-through electrochemical reaction cells, important parameters reported are $\mathrm{pH}$, electrode voltage, organic modifier content, and flow rate $[5,6]$. Several techniques can be used to find the optimal conditions. Those include cyclic voltammetry, direct EC-MS coupling, and off-line EC and LC-MS experiments [5, 22]. The latter method was applied in this study. We evaluated per substrate four different potentials $(0,0.4,0.8,1.2$, and $1.5 \mathrm{~V})$ and four different $\mathrm{pH}$ values $(3.5,5.0,7.0$, and 10.0). The four different buffers used to vary the $\mathrm{pH}$ were: an ammonium formate/formic acid buffer with $\mathrm{pH} 3.5$, an ammonium acetate/acetic acid buffer with $\mathrm{pH}$ 5.0, and two ammonium hydrogen carbonate buffers with $\mathrm{pH} 7.0$ and 10.0, adjusted with formic acid and sodium hydroxide, respectively. Each series resulted in 20 samples. The series was injected in duplicate, which due to the $30 \mathrm{~min}$ LC run time resulted in a well-defined $10 \mathrm{~h}$ difference between the two duplicate analyses of the same sample. This provided an indication of the stability of the products formed.

From the off-line optimization data, optimum conditions were selected to be applied in the on-line mode, using the complete setup. These conditions are summarized for the three model compounds in Table 1.

Table 1 Optimized electrochemical conversion conditions for DMPIP, BIRB796, and SB203580

\begin{tabular}{lcll}
\hline Inhibitor & \multicolumn{2}{c}{ EC conditions } & \\
\cline { 2 - 4 } & $\mathrm{pH}$ & Potential & \\
\hline DMPIP & 3.5 & $+1.2 \mathrm{~V}$ & $-1.5 \mathrm{~V}$ \\
& 10.0 & $+1.2 \mathrm{~V}$ & \\
BIRB796 & 3.5 & $+0.8 \mathrm{~V}$ & \\
& 10.0 & $+0.8 \mathrm{~V}$ & \\
SB203580 & 5.0 & $+1.5 \mathrm{~V}$ & \\
& 10.0 & $+1.5 \mathrm{~V}$ \\
\hline
\end{tabular}

\section{Results and discussion}

In this study, an integrated approach is developed for the formation, identification, and biological characterization of conversion products derived from p $38 \alpha$ kinase inhibitors. This work demonstrates the hyphenation of an electrochemical reaction cell with a continuous-flow bioaffinity assay and parallel LC-HR-MS. The recently developed p38 $\alpha$ bioaffinity assay, based on fluorescence enhancement, was used as a model assay to investigate the possibilities of this combination, but the approach is not limited to this specific continuous-flow assay. Parallel HR-MS ${ }^{\mathrm{n}}$ experiments provide information on the identity of binders and non-binders. Finally, the data produced with this on-line system were compared to that of off-line generated electrochemical conversion products.

First of all, the electrochemical conversion of the kinase inhibitors had to be optimized for substrate conversion and product formation. Formation and identification of bioaffinity products is the ultimate goal of the method. High substrate conversion simplifies the bioaffinity assessment by reducing the interference of the unmodified inhibitor. The off-line and on-line approaches employ the same flowthrough EC instrument which is operated under the same experimental conditions in both cases. Therefore, the offline data generated for validation of the on-line setup can be used to extract the optimal electrochemical reaction conditions for both setups. An excerpt of the off-line generated data can be found in the Electronic Supplementary Material Figure S2. Although the EC and LC-MS approach can be considered laborious for reaction optimization only, it has advantages over other methods. Cyclic voltammetry will not give any information on product formation and direct ECMS analysis can be strongly hampered by ion suppression effects as well as by unwanted up front fragmentation.

Figure 3 shows an overlay of the bioaffinity traces of online electrochemistry-LC-p38 $\alpha$ bioaffinity assay experiments and the relevant extracted ion chromatograms (EIC) from the simultaneous LC-MS experiments for the compound DMPIP $\left(\mathrm{C}_{28} \mathrm{H}_{30} \mathrm{ClFN}_{4} \mathrm{O}_{4},[\mathrm{M}+\mathrm{H}]^{+}\right.$with $\mathrm{m} / \mathrm{z}$ 541.2012). Clearly, bioactive products were formed under all conditions applied, although in different relative concentrations. The four negative peaks in the affinity chromatogram indicate binding/affinity of three conversion products to the p38 $\alpha$ kinase by displacing the tracer ligand upon elution from the LC column. The affinity is linked in the same figure to the EIC for identification of the binders. As the products showing affinity are the same under all conditions, the EICs are derived from one measurement. As reported previously, the retention times in the bioaffinity detection as well as in the MS detection are very stable ( $<3 \%$ relative standard deviation) [18]. This is expectable with state-of-the-art LC equipment, even more so with 


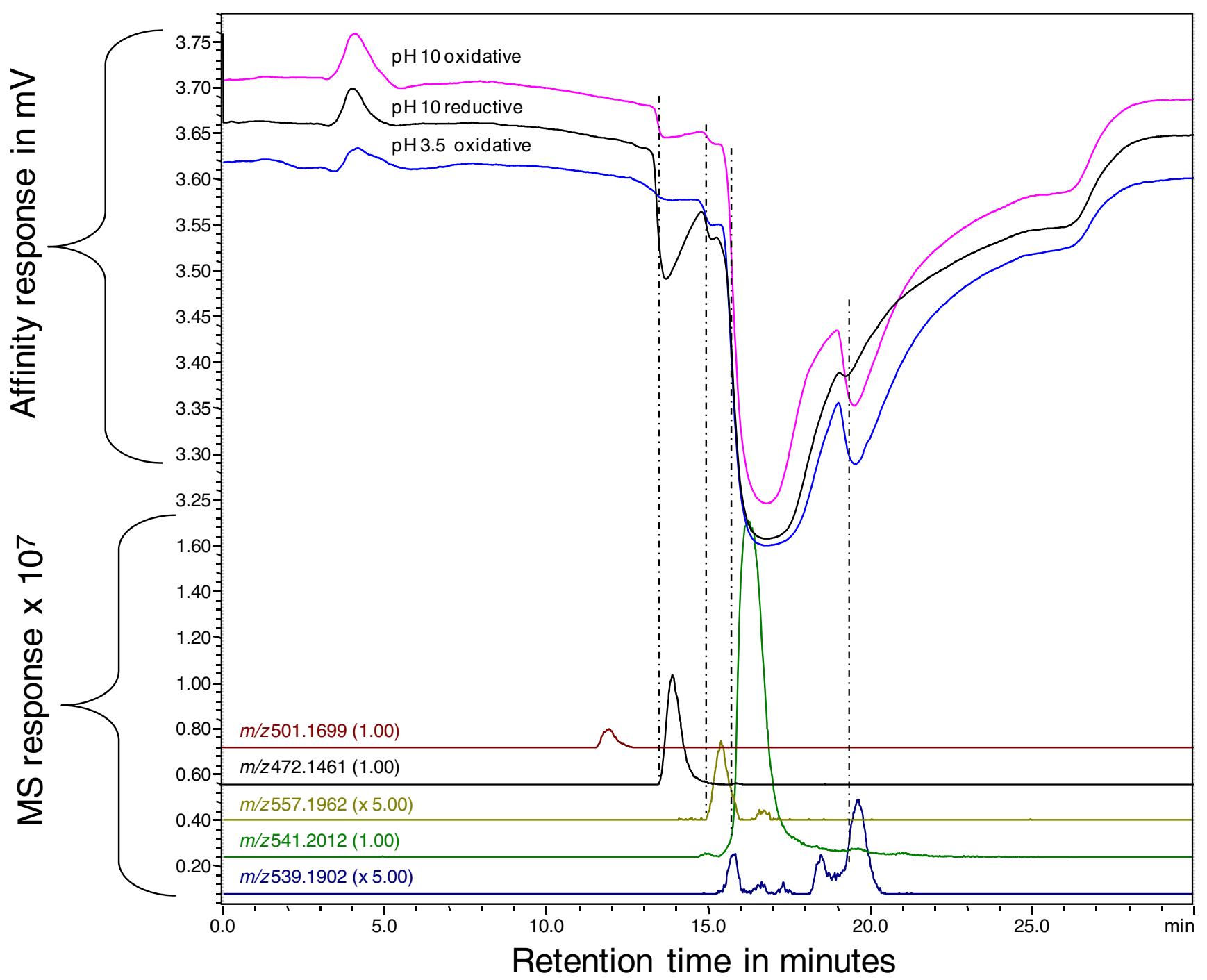

Fig. 3 Correlation of bioaffinity profiles (top) and HR-MS traces (bottom) of electrochemical conversion products related to DMPIP

reagent delivery through pump, pulse dampener, restriction capillary and superloop which ensures stability of the bioaffinity trace. An increase in peak tailing is the only difference expected between bioaffinity and MS chromatograms in terms of chromatographic parameters. Even this only applies to highly nonpolar compounds as a result of the low organic modifier content of the bioaffinity assay. Therefore, the bioaffinity and MS chromatograms are matched by their stable retention time difference. The validity of this retention time difference can be double checked if a known binder is present in the mixture, in this case the substrate of the EC. The correlation of a bioaffinity peak with an EIC peak is achieved with high certainty because a margin of twice the maximum relative standard deviation of the retention time, in this case ca $30 \mathrm{~s}$, is applied. If more than two EIC peaks would be matched within $\pm 30 \mathrm{~s}$ to a bioaffinity peak, both compounds were possibly responsible for the bioaffinity signal. Fortunately, this case did not occur in the investigation. Please note that bioaffinity chromatograms were correlated with EIC at the front of the peak. In this way, peaks are more easily assessed when overloading of either readout leads to broad peaks with poorly defined maxima.

The major affinity peak is due to the unmodified kinase inhibitor, DMPIP. The seemingly large broadening of this affinity peak is due to the sigmoidal dose-response character of the bioassay. Based on the bioaffinity profile, the product with $m / z 539.1902(\Delta-2.011 \mathrm{u})$ showed to be the main bioactive product in the oxidative mode. However, in the reductive mode, this product was less abundant and a product with $m / z 472.1461(\Delta-69.0551 \mathrm{u})$ also showed significant binding to the $\mathrm{p} 38 \alpha$ kinase. In both the reductive and the oxidative mode, a minor affinity peak was observed corresponding to hydroxylated DMPIP, with $\mathrm{m} / z 557.1962$ $(\Delta+15.9950 \mathrm{u})$.

Identification of the (bioactive) products was done using the HR-MS ${ }^{\mathrm{n}}$ data obtained in parallel with the bioaffinity 
measurements. Based on the fragmentation of the unmodified kinase inhibitor, the sites of modification were identified as far as possible. The fragmentation of DMPIP allowed the annotation of characteristic fragments to be used for the determination of the modification sites. Figure 4 shows the structure of DMPIP with the characteristic parts of the molecule involved in the fragmentation reactions.

Important fragments observed in the MS/MS spectra of DMPIP are C + D with $\mathrm{m} / \mathrm{z} 319.0480$ and C with $\mathrm{m} / \mathrm{z}$ 206.0003. Table 2 summarizes the identification study.

Below, the MS structure elucidation of two ions is discussed in detail. A full description of the structure elucidation for all ions observed is avoided in order to focus the discussion on the innovative combination of techniques. As an example, the MS and MS/MS spectra for the bioactive product with $\mathrm{m} / \mathrm{z} 472.1461$ are given in Fig. 5. The $\mathrm{m} / \mathrm{z}$ difference compared to the parent compound is $\Delta$ $-69.0551 \mathrm{u}$, consistent with a net loss of $\mathrm{C}_{4} \mathrm{H}_{7} \mathrm{~N}$. The data indicate that the molecule is modified in the $\mathrm{D}$ part, see Fig. 4. Parts $\mathrm{A}+\mathrm{B}$ and $\mathrm{C}$ are detected unmodified, whilst the fragment of $\mathrm{C}+\mathrm{D}$ shows the net loss of $\mathrm{C}_{4} \mathrm{H}_{7} \mathrm{~N}$. Fragmentation of the $[\mathrm{M}+\mathrm{H}]^{+}$additionally results in de neutral loss of $\mathrm{CO}_{2}$, leading to an unmodified $\mathrm{B}+\mathrm{C}$ fragment. The characteristic losses of $\mathrm{C}_{4} \mathrm{H}_{7} \mathrm{~N}$ and $\mathrm{CO}_{2}$ prove the hydrolysis of the amide in part $\mathrm{D}$ to a carboxylic acid, which is further supported by the $\mathrm{MS}^{3}$ fragments (data not shown). Therefore, full structure elucidation could be achieved by $\mathrm{MS}^{\mathrm{n}}$ analysis for this product. For the product with $\mathrm{m} / \mathrm{z}$ 539.1902 , attributed to a dehydrogenation of part B, absolute identification is not possible. The attribution is made by exclusion. As fragment CD is observed unchanged, modification in parts $\mathrm{C}$ and $\mathrm{D}$ is excluded. Since the dehydrogenation is observed in a $\mathrm{BC}$ fragment and $\mathrm{C}$ has already been excluded, the modification has to be in part $\mathrm{B}$. A modification 'across' parts $\mathrm{B}$ and $\mathrm{C}$ can also be excluded, as the connecting amide has no hydrogen atoms to lose and as any other possibility would have to involve the formation of a new bond. This would require proximity which is hindered by the rigid structure of the $\mathrm{C}$ part and the connecting amide. The only likely crosslink between $\mathrm{B}$ and $\mathrm{C}$ would produce the loss of $\mathrm{HCl}$ instead of $\mathrm{H}_{2}$. All other $\mathrm{B}-\mathrm{C}$ crosslinks would lead to new carbon-carbon bonds which would block the formation of the $\mathrm{CD}$ fragment.

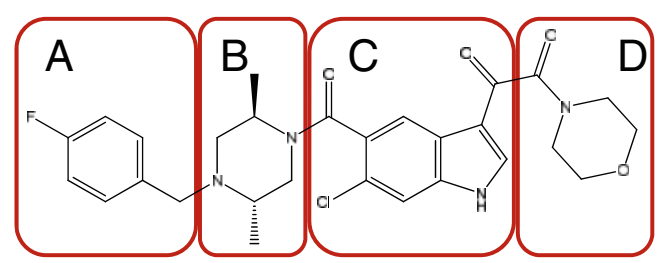

Fig. 4 Structure of DMPIP and characteristic parts for MS/MS identification of electrochemical conversion products
Other products were identified in a similar way. The products of oxidation in part $\mathrm{D}(\mathrm{m} / \mathrm{z} 472.1461$ and $\mathrm{m} / \mathrm{z} 557.1962)$ as well as dehydrogenation in part B $(\mathrm{m} / z$ 539.1902) of DMPIP all retained the affinity for the $\mathrm{p} 38 \alpha$ kinase, see Table 2. Products not showing bioaffinity include methoxylation of part A ( $m / z 571.2110, \mathrm{C}_{29} \mathrm{H}_{33} \mathrm{ClFN}_{4} \mathrm{O}_{5}{ }^{+}$; see also below), cleavage of methane from part $\mathrm{B}(\mathrm{m} / \mathrm{z} 525.1720$, $\left.\mathrm{C}_{27} \mathrm{H}_{27} \mathrm{ClFN}_{4} \mathrm{O}_{4}{ }^{+}\right)$and the loss of $\mathrm{C}_{3} \mathrm{H}_{4}$ from part B $(\mathrm{m} / \mathrm{z}$ $501.1715, \mathrm{C}_{25} \mathrm{H}_{27} \mathrm{ClFN}_{4} \mathrm{O}_{4}{ }^{+}$). The electrochemically induced cleavage of part A resulted in a product with $\mathrm{m} / \mathrm{z} 431.1476$ $\left(\mathrm{C}_{21} \mathrm{H}_{24} \mathrm{ClN}_{4} \mathrm{O}_{4}{ }^{+}\right)$.

The bioaffinity assessment of the products based on the inhibitor BIRB796 $\left(\mathrm{C}_{31} \mathrm{H}_{37} \mathrm{~N}_{5} \mathrm{O}_{3},[\mathrm{M}+\mathrm{H}]^{+}\right.$with $\mathrm{m} / \mathrm{z}$ 528.2975) showed that next to BIRB796 itself, two bioactive electrochemical conversion products were formed. Figure 6 shows the extracted ion chromatograms of the three bioactive compounds aligned with the bioaffinity trace. The two additional bioactive compounds were the main conversion products, being identified as the quinoneimine $(\mathrm{m} / \mathrm{z}$ 413.1985, $\mathrm{C}_{25} \mathrm{H}_{25} \mathrm{~N}_{4} \mathrm{O}_{2}{ }^{+}, \Delta 115.0990 \mathrm{u}$ ) and the hydroquinone $\left(m / z 415.2134, \mathrm{C}_{25} \mathrm{H}_{27} \mathrm{~N}_{4} \mathrm{O}_{2}{ }^{+}, \Delta 113.0841 \mathrm{u}\right)$, both being present in all conversion samples.

Interestingly, Regan et al. described the structure-activity relationships of BIRB796 and some of its fragments [23]. The hydroquinone was found to bind to the kinase, while the reactive quinoneimine was addressed neither in this publication nor elsewhere in literature. The fact that we can detect bioaffinity of the reactive quinoneimine underlines the importance of a quick and clean sample handling technology between formation and analysis of the conversion products. In this respect, our on-line approach can be of added value with respect to the assessment of the affinity of reactive species. Other electrochemical conversion products of BIRB796 were not bioactive. These included a product with $\mathrm{m} / \mathrm{z}$ 230.1652 corresponding to $\mathrm{C}_{14} \mathrm{H}_{20} \mathrm{~N}_{3}{ }^{+}$and a low abundant product with $m / z 273.1710$ corresponding to $\mathrm{C}_{15} \mathrm{H}_{21} \mathrm{~N}_{4} \mathrm{O}_{\text {, }}^{+}$ co-eluting with the unmodified BIRB796. Structure proposals can be found in the Electronic Supplementary Material Figure S1. Oxidation at $\mathrm{pH} 7.0$ and 10.0 resulted in two additional products with $m / z 386.1863\left(\mathrm{C}_{24} \mathrm{H}_{24} \mathrm{~N}_{3} \mathrm{O}_{2}{ }^{+}\right)$and $411.1821\left(\mathrm{C}_{25} \mathrm{H}_{23} \mathrm{~N}_{4} \mathrm{O}_{2}{ }^{+}\right)$.

For SB203580 and its conversion products, affinity determination was hampered by the auto-fluorescence of SB203580 and its products at the wavelengths used for the detection of the enzyme-tracer complex in the p $38 \alpha$ bioaffinity assay. Electrochemical conversion of SB203580 $\left(\mathrm{C}_{21} \mathrm{H}_{17} \mathrm{FN}_{3} \mathrm{OS}^{+},[\mathrm{M}+\mathrm{H}]^{+}\right.$ with $\mathrm{m} / \mathrm{z} 378.1071)$ resulted in the formation of single $(\mathrm{m} / \mathrm{z}$ 394.1026) and double oxygenated analogues $(\mathrm{m} / \mathrm{z} 410.0969)$. The main product could be identified as the sulfone product based on its fragmentation pattern described previously by Henklova et al. [24]. The rather scarce fragmentation of SB203580 did not allow proposing structures of the other products generated by electrochemical conversion. 
Table 2 Identification of electrochemical conversion products related to DMPIP based on high resolution MS $^{\mathrm{n}}$ experiments (for explanation: see text)

\begin{tabular}{|ccclcccc|}
\hline $\mathbf{T}_{\mathbf{r}}$ in min. & {$[\mathbf{M + H}]^{+}$} & $\begin{array}{l}\text { Change } \\
\text { in } \\
\text { formula }\end{array}$ & $\begin{array}{l}\text { Molecular } \\
\text { formula }\end{array}$ & $\begin{array}{c}\text { MS } \\
\mathbf{A B}\end{array}$ & $\mathbf{C}$ & $\mathbf{C D}$ & $\begin{array}{c}\text { other } \\
\text { fragments }\end{array}$ \\
\hline 16.1 & 541.2012 & - & $\mathrm{C}_{28} \mathrm{H}_{31} \mathrm{ClFN}_{4} \mathrm{O}_{4}^{+}$ & $\sqrt{ }$ & $\sqrt{ }$ & $\sqrt{ }$ & - \\
\hline 9.3 & 431.1481 & $-\mathrm{C}_{7} \mathrm{H}_{6} \mathrm{~F}$ & $\mathrm{C}_{21} \mathrm{H}_{25} \mathrm{ClN}_{4} \mathrm{O}_{4}^{+}$ & - & $\sqrt{ }$ & - & $\mathrm{D}$ \\
\hline 11.9 & 501.1699 & $-\mathrm{C}_{3} \mathrm{H}_{4}$ & $\mathrm{C}_{25} \mathrm{H}_{27} \mathrm{ClFN}_{4} \mathrm{O}_{4}^{+}$ & - & - & $\sqrt{ }$ & ${\mathrm{BC}-\mathrm{C}_{3} \mathrm{H}_{4}}^{+}$ \\
\hline 12.8 & 525.1699 & $-\mathrm{CH}_{4}$ & $\mathrm{C}_{27} \mathrm{H}_{27} \mathrm{ClFN}_{4} \mathrm{O}_{4}{ }^{+}$ & $-\mathrm{CH}_{4}$ & - & $\sqrt{ }$ & - \\
\hline 14.0 & 472.1461 & $-\mathrm{C}_{4} \mathrm{H}_{7} \mathrm{~N}$ & $\mathrm{C}_{24} \mathrm{H}_{24} \mathrm{ClFN}_{3} \mathrm{O}_{4}{ }^{+}$ & $\sqrt{ }$ & $\sqrt{ }$ & $-\mathrm{C}_{4} \mathrm{H}_{7} \mathrm{~N}$ & $-\mathrm{CO}_{2}$ \\
\hline 15.6 & 557.1962 & $+\mathrm{O}_{28}$ & $\mathrm{C}_{28} \mathrm{H}_{31} \mathrm{ClFN}_{4} \mathrm{O}_{5}^{+}$ & $\sqrt{ }$ & $\sqrt{ }$ & $+\mathrm{O}$ & - \\
\hline 15.6 & 529.1649 & $-\mathrm{C}_{2} \mathrm{H}_{4}+\mathrm{O}$ & $\mathrm{C}_{26} \mathrm{H}_{27} \mathrm{ClFN}_{4} \mathrm{O}_{5}{ }^{+}$ & & - & $\sqrt{ }$ & $\mathrm{A}$, \\
\hline 17.5 & 571.2118 & $+\mathrm{CH}_{2} \mathrm{O}$ & $\mathrm{C}_{29} \mathrm{H}_{33} \mathrm{ClFN}_{4} \mathrm{O}_{5}^{+}$ & - & - & $\sqrt{ }$ & $\mathrm{D},-\mathrm{H}_{2} \mathrm{CO}$ \\
\hline 19.6 & 539.1902 & $-2 \mathrm{H}$ & $\mathrm{C}_{28} \mathrm{H}_{29} \mathrm{ClFN}_{4} \mathrm{O}_{4}^{+}$ & - & - & $\sqrt{ }$ & $\mathrm{BC}-2 \mathrm{H}$ \\
\hline
\end{tabular}

MS fragmentation is not to be confused with EC modifications (e.g., hydrolysis). For conclusions on nature and site of the EC modifications drawn from the $\mathrm{MS}^{\mathrm{n}}$ data, please refer to the text. Binding to $\mathrm{p} 38 \alpha$ kinase is defined as an $\mathrm{S} / \mathrm{N}$ ratio of $>3$ in the $\mathrm{p} 38 \alpha$ bioaffinity assay (see also Fig. 3 ). The products showing bioaffinity are underlined in gray

In order to compare the on-line formation with the conventional off-line generated products, a set of off-line electrochemical conversion experiments was conducted. This included variation of $\mathrm{pH}$ and electrochemical potential for the conversion of the inhibitors. The samples were measured twice, once immediately after generation and once with an additional storage time of $10 \mathrm{~h}$. In this way, a focus was set on the effects of storage as a major difference between the off-line and on-line approach. For DMPIP and SB203580, no differences were observed in the conversion profiles between off-line and on-line conversion and analysis. This means that product formation is comparable between the two modes. The results of the off-line experiments also help to explain the origin of the methoxylation product for DMPIP. It may be suggested that the methoxylation does not take place in the EC cell, but rather via a reaction of a
Fig. $5 \mathrm{MS}$ and MS/MS spectra of the electrochemical conversion product of DMPIP, with $m / z$ 472.1461. Annotations related to the parent structure (Fig. 4) are included in the spectra
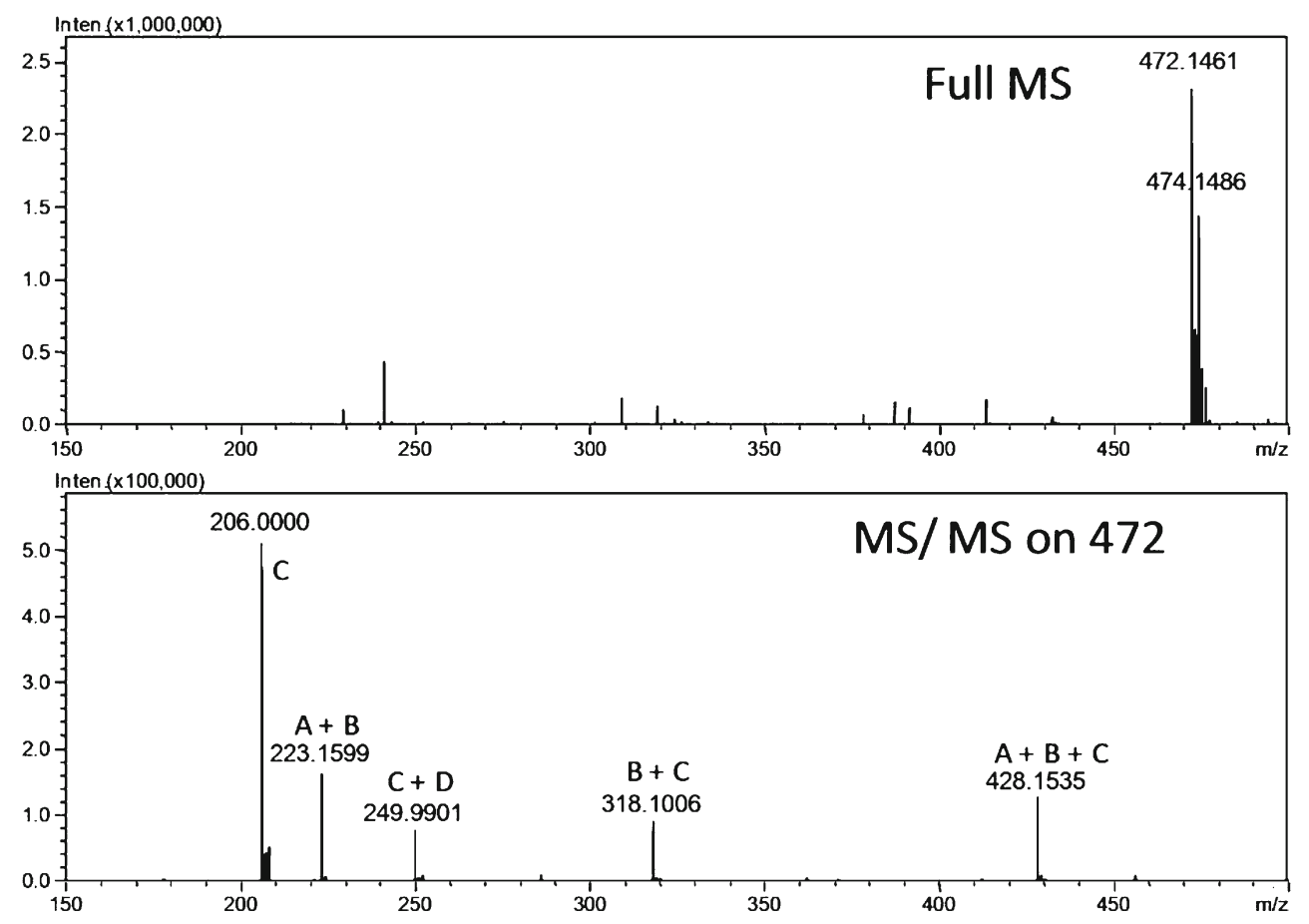
Fig. 6 Correlation of bioaffinity profiles (top) and HR-MS traces (bottom) of electrochemical conversion products related to BIRB796, conversion at $\mathrm{pH} 3.5$ with $0.8 \mathrm{~V}$

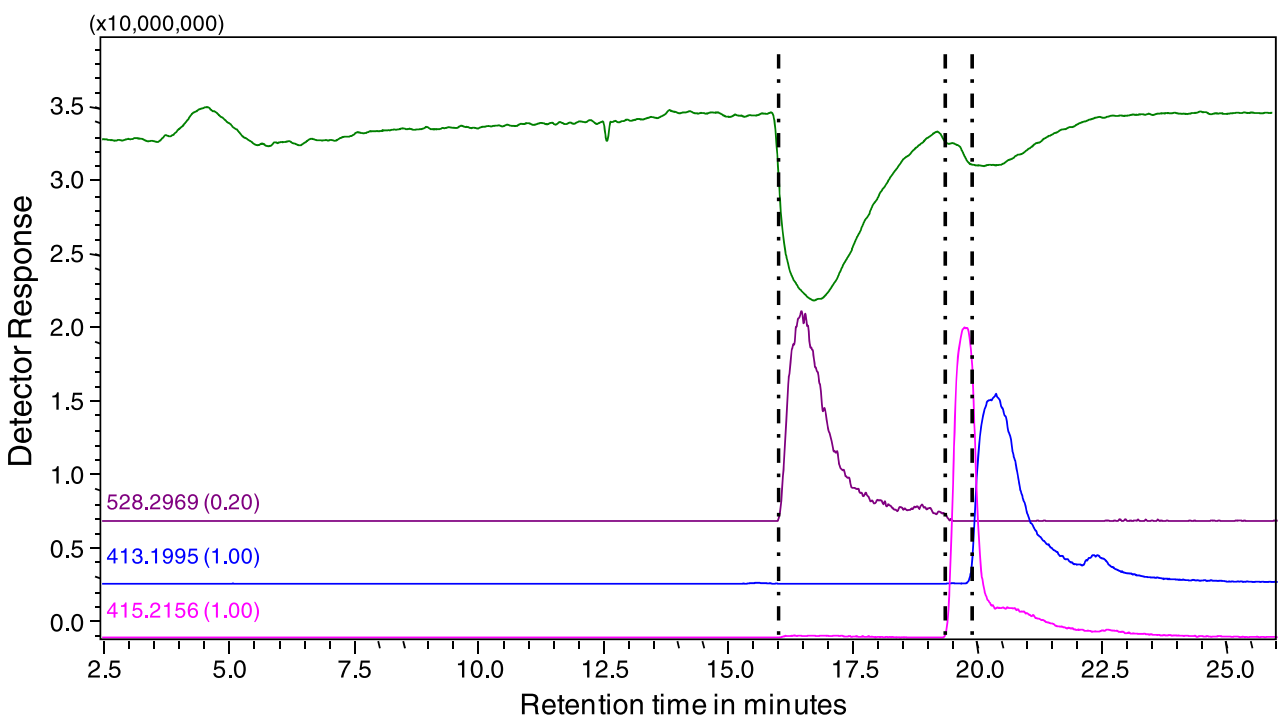

reactive intermediate with methanol in the LC mobile phase. However, the off-line experiments provide evidence against this. The off-line data, shown in Electronic Supplementary Material Figure S3, are not consistent with an intermediate reaction with the LC eluent because, if it would be reacting, the amount of methoxylated product should be the same or less after storage (depending on the stability of the intermediate). However, the data actually show a higher abundance of methoxylated product after storage which indicates a reaction of an intermediate within the EC reaction mixture. Furthermore, if a reaction would take place during the chromatographic step, the peak shape of the methoxylated product would be seriously deteriorated. This is not observed. For BIRB796, differences were observed between off-line and on-line conversion products. The peak area of the reactive quinoneimine significantly decreased in the duplicate measurement after $10 \mathrm{~h}$ (see Electronic Supplementary Material Figure S2), whilst in the $\mathrm{pH} 7$ samples the hydroquinone was only present after $10 \mathrm{~h}$. The products with $\mathrm{m} / \mathrm{z} 230$ and $\mathrm{m} / \mathrm{z} 273 \mathrm{had}$ an increased peak area in all duplicate samples and can therefore be either considered as secondary conversion products or degradation products. This is a direct consequence of the storage and handling steps and can be avoided in the on-line approach presented in this paper.

\section{Conclusion}

Electrochemical conversion of drug molecules has already been demonstrated to be a valuable tool to assist in drug metabolite identification studies. As an additional valuable feature, we showed that electrochemistry coupled on-line with LC-MS/bioassay can be used for the generation of small focused libraries of bioactive structures closely resembling the parent structures and assessment of their bioaffinity profile. The hit rate in these focused libraries can be significant. With the integration of direct affinity assessment of the electrochemical conversion products, one can quickly determine critical positions of a molecule influencing its affinity towards the target protein. Moreover, the on-line hyphenation of formation with identification and affinity determination strategies allows the affinity assessment of reactive species since sample handling steps and times are significantly reduced. The latter was clearly demonstrated by the affinity determination of the reactive quinoneimine of the BIRB796 inhibitor. All of these results stress the importance of employing biological characterization as an integral part of EC studies concerned with drug metabolism or lead discovery/optimization.

In principle, the on-line integrated setup could be expanded to an automated system applicable in routine analysis. Instead of by infusion, the parent compounds could be flow-injected into the electrochemical reaction cell. Solvent select valves could be used for convenient and automated changing of the solvent composition and $\mathrm{pH}$. Evidently, the subsequent electrochemical conversion can also be fully automated and controlled via the appropriate controlling software during the analytical runs. The complete setup should be capable of implementation in fully automated and integrated analytical workflows in drug discovery laboratories.

Acknowledgments This research was performed within the framework of project D2-102 "Metabolic Stability Assessment" of the Dutch Top Institute Pharma. We thank Junella Antonie for technical assistance. The invaluable discussions with the analytical chemistry group of the Münster University, especially Uwe Karst and Anne Baumann, are gratefully acknowledged. Further thanks go to Jean-Pierre Chervet and Agnieszka Kray of Antec Leiden B.V. for the initial loan of the Roxy EC system and continued technical support. 
Open Access This article is distributed under the terms of the Creative Commons Attribution Noncommercial License which permits any noncommercial use, distribution, and reproduction in any medium, provided the original author(s) and source are credited.

\section{References}

1. Nouri-Nigjeh E, Bischoff R, Bruins AP, Permentier HP (2011) Electrochemistry in the mimicry of oxidative drug metabolism by cytochrome p450s. Curr Drug Metab 12(4):359-371

2. Thevis M, Lohmann W, Schrader Y, Kohler M, Bornatsch W, Karst U, Schanzer W (2008) Use of an electrochemically synthesised metabolite of a selective androgen receptor modulator for mass spectrometrybased sports drug testing. Eur J Mass Spectrom 14(3):163-170

3. Madsen KG, Gronberg G, Skonberg C, Jurva U, Hansen SH, Olsen J (2008) Electrochemical oxidation of troglitazone: identification and characterization of the major reactive metabolite in liver microsomes. Chem Res Toxicol 21(10):2035-2041

4. Hillard EA, de Abreu FC, Ferreira DCM, Jaouen G, Goulart MOF, Amatore C (2008) Electrochemical parameters and techniques in drug development, with an emphasis on quinones and related compounds. Chem Commun (Cambridge, U K) 23(23):2612-2628

5. Baumann A, Karst U (2010) Online electrochemistry/mass spectrometry in drug metabolism studies: principles and applications. Expert Opin Drug Metab Toxicol 6(6):715-731

6. Jurva U, Wikstrom HV, Weidolf L, Bruins AP (2003) Comparison between electrochemistry/mass spectrometry and cytochrome p450 catalyzed oxidation reactions. Rapid Commun Mass Spectrom 17 (8):800-810

7. Baumann A, Lohmann W, Schubert B, Oberacher H, Karst U (2009) Metabolic studies of tetrazepam based on electrochemical simulation in comparison to in vivo and in vitro methods. $J$ Chromatogr A 1216(15):3192-3198

8. Tong W, Chowdhury SK, Su AD, Alton KB (2010) Quantitation of parent drug and its unstable metabolites by in situ coulometric oxidation and liquid chromatography-tandem mass spectrometry. Anal Chem 82(24):10251-10257

9. Goyal RN, Garg DK (1996) Electro-oxidation of the neurotoxin 5,6-dihydroxytryptamine and effects of its oxidation products in mice. Bioelectrochem Bioenerg 39(2):249-257

10. Felim A, Urios A, Neudorffer A, Herrera G, Blanco M, Largeron M (2007) Bacterial plate assays and electrochemical methods: An efficient tandem for evaluating the ability of catechol-thioether metabolites of mdma ("Ecstasy") to induce toxic effects through redox-cycling. Chem Res Toxicol 20(4):685-693

11. Kool J, Giera M, Irth H, Niessen W (2011) Advances in mass spectrometry-based post-column bioaffinity profiling of mixtures. Anal Bioanal Chem 399:2655-2668

12. de Vlieger JSB, Kolkman AJ, Ampt KAM, Commandeur JNM, Vermeulen NPE, Kool J, Wijmenga SS, Niessen WMA, Irth H, Honing M (2010) Determination and identification of estrogenic compounds generated with biosynthetic enzymes using hyphenated screening assays, high resolution mass spectrometry and off-line nmr. J Chromatogr B 878(7-8):667-674

13. Marques LA, Kool J, de Kanter F, Lingeman H, Niessen W, Irth H (2010) Production and on-line acetylcholinesterase bioactivity profiling of chemical and biological degradation products of tacrine. J Pharm Biomed Anal 53(3):609-616

14. Giera M, de Vlieger JSB, Lingeman H, Irth H, Niessen WMA (2010) Structural elucidation of biologically active neomycin noctyl derivatives in a regioisomeric mixture by means of liquid chromatography/ion trap time-of-flight mass spectrometry. Rapid Commun Mass Spectrom 24(10):1439-1446

15. Jonker N, Kool J, Krabbe JG, Retra K, Lingeman H, Irth H (2008) Screening of protein-ligand interactions using dynamic protein-affinity chromatography solid-phase extraction-liquid chromatography-mass spectrometry. J Chromatogr A 1205(12):71-77

16. de Boer AR, Alcaide-Hidalgo JM, Krabbe JG, Kolkman J, Boas CNV, Niessen WMA, Lingeman H, Irth H (2005) High-temperature liquid chromatography coupled on-line to a continuous-flow biochemical screening assay with electrospray ionization mass spectrometric detection. Anal Chem 77(24):7894-7900

17. Heus F, Giera M, de Kloe GE, van Iperen D, Buijs J, Nahar TT, Smit AB, Lingeman H, de Esch IJP, Niessen WMA, Irth H, Kool J (2010) Development of a microfluidic confocal fluorescence detection system for the hyphenation of nano-lc to on-line biochemical assays. Anal Bioanal Chem 398(7-8):3023-3032

18. Falck D, de Vlieger JSB, Niessen WMA, Kool J, Honing M, Giera M, Irth H (2010) Development of an online p38 alpha mitogenactivated protein kinase binding assay and integration of lc-hr-ms. Anal Bioanal Chem 398(4):1771-1780

19. Sperry JB, Whitehead CR, Ghiviriga I, Walczak RM, Wright DL (2004) Electrooxidative coupling of furans and silyl enol ethers: application to the synthesis of annulated furans. J Org Chem 69 (11):3726-3734

20. Zhang JY, Shen BF, Lin AN (2007) Novel strategies for inhibition of the p38 mapk pathway. Trends Pharmacol Sci 28(6):286295

21. Schindler JF, Monahan JB, Smith WG (2007) P38 pathway kinases as anti-inflammatory drug targets. J Dent Res 86(9):800-811

22. Tahara K, Nishikawa T, Hattori Y, Iijima S, Kouno Y, Abe Y (2009) Production of a reactive metabolite of troglitazone by electrochemical oxidation performed in nonaqueous medium. $\mathrm{J}$ Pharm Biomed Anal 50(5):1030-1036

23. Regan J, Capolino A, Cirillo PF, Gilmore T, Graham AG, Hickey E, Kroe RR, Madwed JR, Moriak M, Nelson R, Pargellis CA, Swinamer A, Torcellini C, Tsang M, Moss N (2003) Structure-activity relationships of the p38 alpha map kinase inhibitor 1-(5-tert-butyl-2-p-tolyl2 h-pyrazol-3-yl)-3-[4-(2-morpholin-4-yl-ethoxy)naphthalen-1-yl] urea (birb 796). J Med Chem 46(22):4676-4686

24. Henklova P, Vrzal R, Papouskova B, Bednar P, Jancova P, Anzenbacherova E, Ulrichova J, Maurel P, Pavek P, Dvorak Z (2008) Sb203580, a pharmacological inhibitor of p38 map kinase transduction pathway activates erk and jnk map kinases in primary cultures of human hepatocytes. Eur J Pharmacol 593(1-3):16-23 